Proceedings of the 47th International School and Conference on the Physics of Semiconductors "Jaszowiec 2018"

\title{
Study of the Effectiveness of Anodic Films as Surface Passivation for InAsSb Mid-Wave Infrared HOT Detectors
}

\author{
K. Michalczewski ${ }^{a * *}$, E. GomóŁka ${ }^{a}$, J. Ciosek ${ }^{b}$, Ł. Kubiszyn ${ }^{c}$, D. Benyahia ${ }^{a}$, K. Lipski ${ }^{a}$, \\ P. MARTYNiUk ${ }^{a}$, J. PiOtrowski $^{c}$ AND A. Rogalski ${ }^{a}$ \\ ${ }^{a}$ Institute of Applied Physics, Military University of Technology, gen. W. Urbanowicza 2, 00-908 Warsaw, Poland \\ ${ }^{b}$ Institute of Optoelectronics, Military University of Technology, gen. W. Urbanowicza 2, 00-908 Warsaw, Poland \\ ${ }^{c}$ Vigo System S.A., Poznańska 129/133, 05-850 Ożarów Mazowiecki, Poland
}

\begin{abstract}
We report on the influence of different anodic films on surface leakage current for $\operatorname{InAs}_{1-x} \operatorname{Sb}_{x}(x=0.195)$ high operation temperature (HOT) photodiode grown on GaAs substrate. The electrochemical passivation technique was proposed to modify the mesa sidewalls properties and obtain anodic coatings covered by photoresist. The electrical behavior of sulphur, fluoride, and chloride anodic films with photoresist and unpassivated devices was compared. The X-ray photoelectron spectroscopy shows the highest suppression of oxygen (O) $1 s$ peak for sulphur anodic film. In the fluorine anodic films surface is reoxidized and surface leakage current increases by two orders of magnitude. The passivation with sulphur and chloride treatment was not destructive to InAsSb diode. Sulphur anodic film has been highlighted as a promising surface passivation layer for barrier detectors.
\end{abstract}

DOI: 10.12693 /APhysPolA.134.981

PACS/topics: 73.61.Ey, 73.25.+i, 82.45.Cc

\section{Introduction}

The application associated with gas detection $\left(\mathrm{CO}_{2}\right)$ and infrared imaging in the spectral range of $3-5 \mu \mathrm{m}$ have stimulated considerable interest in the development of infrared (IR) detectors especially with InAsSb alloy which is considered as an alternative material for mercurycadmium-telluride (MCT).

It has been known that this material has got a number of advantages as, easy tunable bandgap and high electron mobility at room temperature [1]. The barrier device consisted with such alloy, grown on GaAs substrate is a convenient way to obtain cheap HOT devices which could compete with $\mathrm{HgCdTe}$ technology in terms of stability, cost and performance.

One of the limiting factor which increases the overall dark current of infrared devices is leakage current which is associated with the surface quality. During the detector fabrication from $\mathrm{A}^{I I I} \mathrm{~B}^{V}$ heteroepitaxial structures, the barrier is removed and mesas sidewalls are exposed to aggressive chemicals and atmosphere during etching process. It results in formation of secondary compounds as indium, arsenic, and antimony oxides [2-4]. Some of those oxides are conductive in nature and creates a surface leakage path. The X-ray photoelectron spectroscopy (XPS) measurements $[4,5]$ showed that, after processing, elemental arsenic and antimony are distributed through the native oxide. It causes the formation of conduction channels parallel to the interface which could lead to an increase of the overall dark current.

\footnotetext{
* corresponding author; e-mail: krystian.michalczewski@wat.edu.pl
}

Up to date there is still discussion about the importance of passivation and influence of surface leakage current in III-V materials technology specially at HOT condition. Contrary to the popular believed, that proper device architecture [6, 7] (unipolar barrier, $\mathrm{nBn}$ structure) reduce the surface leakage, X. Du et al. [6] reported an investigation on surface leakage current in $\mathrm{nBn}$ structure. Taking into account that works surface passivation become an absolute necessity to enhance the performance of InAsSb photodiodes.

In this paper we report on a passivation procedure based on two-step technique (photoresist coating after anodic treatment) and we investigate the influence of sulphur, fluoride, and chloric anodic films on the overall dark current in InAsSb HOT devices. The XPS measurements were used to evaluate the surface quality of InAsSb alloy after anodic passivation.

\section{Experiment}

The InAsSb photodiode was grown by a RIBER Compact 21-DZ solid source molecular beam epitaxy (MBE) system, on GaAs (001) substrates. As ${ }_{2}$ and Sb molecules have been obtained by valved cracker arsenic and antimony cell. The substrate temperature was controlled by manipulator thermocouple. Schematic representation of the detector structure with ammonium based compounds for passivation was presented in Fig. 1a. Detector consists of top contact, wide-bandgap barrier for electrons, absorber, gradient doping layer and bottom contact. The main absorber region consists of non-intentionally doped (n.i.d.) InAsSb material with mole fraction $x_{S b}=$ 0.195 . Active layer has a background concentration of $2 \times 10^{16} \mathrm{~cm}^{-3}$ with $n$-type conductivity. This device was optimized for mid-infrared range. Between top contact and absorber layer AlSb electron-blocking barrier 
(a)

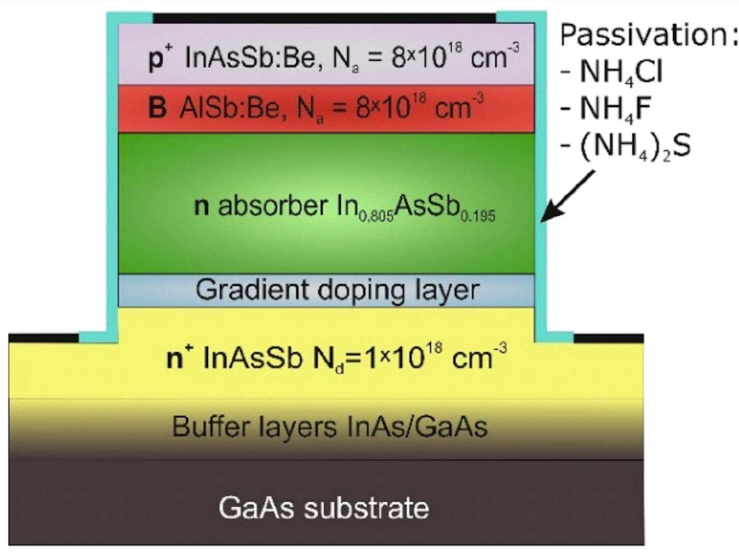

$\xi \xi \xi \xi \xi I R$

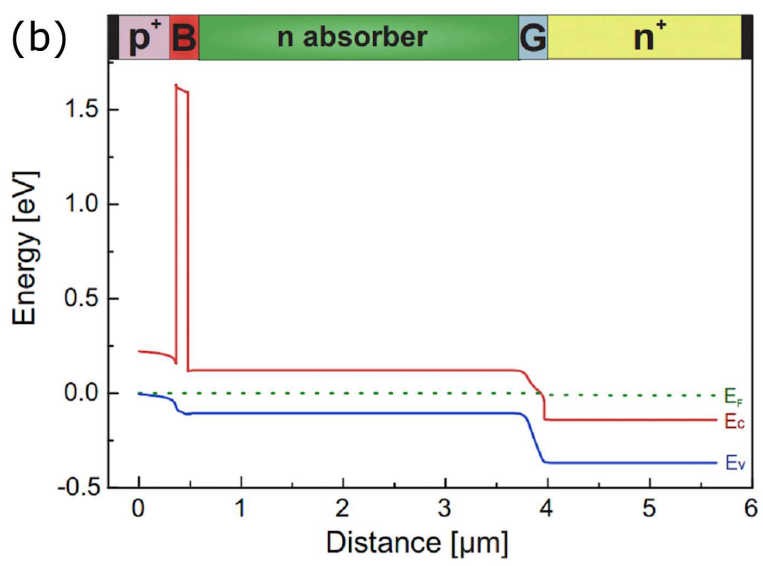

Fig. 1. $p^{+} B_{p} n n^{+}$design heterostructure: schematic representation with passivation (a) and energy band diagram (b).

was implemented. Top and bottom InAsSb contact layers was high doped to generate ohmic contact. The detector heterostructure was simulated with commercially available software APSYS by Crosslight Inc. The modeled energy band diagram profile of the medium-wave infrared (MWIR) structure is presented in Fig. 1b. The calculations were performed for $T=210 \mathrm{~K}$, without bias voltage.

The standard photolithography technique with wet etching was utilized to produce mesas profile. $\mathrm{H}_{3} \mathrm{PO}_{4}: \mathrm{C}_{3} \mathrm{C}_{i}: \mathrm{H}_{2} \mathrm{O}_{2}: \mathrm{HCl}$ solution was used to receive uniform etch depth $5 \mu \mathrm{m}$ which corresponds to the middle of the bottom contact layer of the detector. The electrochemical passivation (ECP) technique was used to produces anodic films on the surface. The set of three solutions were prepared: $20 \%\left(\mathrm{NH}_{4}\right)_{2} \mathrm{~S}$ in $\mathrm{H}_{2} \mathrm{O}, 0.5 \mathrm{M} \mathrm{NH} \mathrm{N}_{4} \mathrm{~F}$ and $0.5 \mathrm{M} \mathrm{NH} \mathrm{NH}_{4} \mathrm{Cl}$. Prior to the $\mathrm{Au}$-contact deposition anodic film from the top and the bottom contact layer was removed with diluted etching solution. The bottom and the top Au contact layers were deposited by electrochemical deposition (ECD). The set of 5 rounded mesas was produced with a diameter respectively $100,200,300,400,500 \mu \mathrm{m}$. The effectiveness of the passivation treatment was evaluated on the base of the dark current density measurement and the XPS measurements.

\section{Results}

Figure 2 shows the measured at $210 \mathrm{~K}$ dark current densities versus applied bias for analyzed barrier detectors: unpassivated and with three different types of passivation layers. The current-voltage characteristics have been measured using the Agilent B2902A sourcemeter connected to the Probe Station Analyzer.

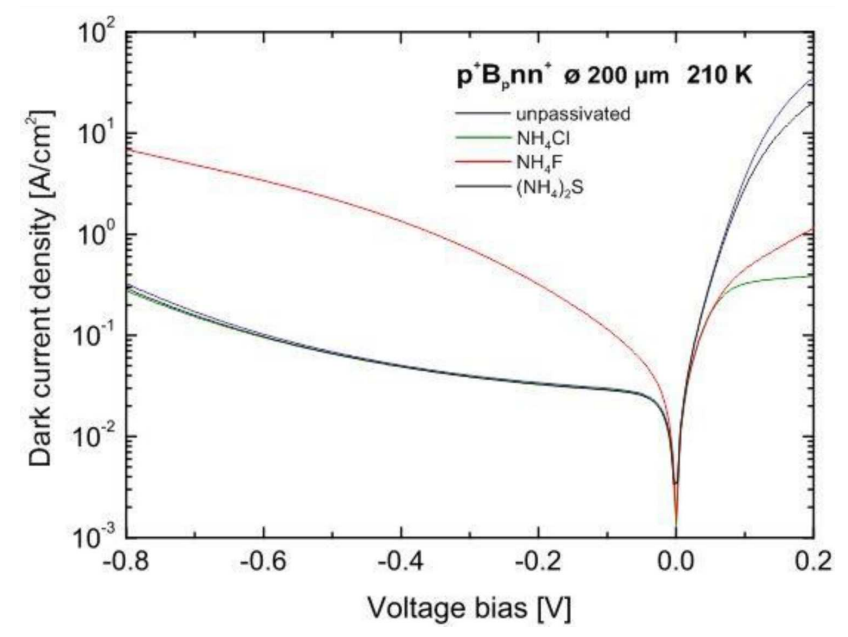

Fig. 2. Dark current density vs. applied bias characteristics of mesa diameter $200 \mu \mathrm{m}$ for $p^{+} B_{p} n n^{+}$passivated and unpassivated detectors at $210 \mathrm{~K}$.

Detector with $\mathrm{NH}_{4} \mathrm{~F}$ ECP with photoresist coating shows the highest values of dark currents. Treatment of the device with other passivation solutions such as $\mathrm{NH}_{4} \mathrm{Cl}$ and $\left(\mathrm{NH}_{4}\right)_{2} \mathrm{~S}$ did not improve device performance compared to unpassivated structure.

For mesa-structure, the dark current can be represented as a sum of bulk and surface dark current according to the equation:

$$
J_{\text {dark }}=J_{\text {bulk }}+J_{\text {surf }} \frac{P}{A},
$$

where $J_{\text {bulk }}$ is the bulk dark current density, $J_{\text {surf }}$ is the surface dark current density and $P / A$ is the perimeter to the cross-sectional area ratio. In order to identify the contribution of $J_{\text {bulk }}$ and $J_{\text {surf }}$ to the dark currents, dark currents density were then measured for a set of detectors, with mesa diameters ranging from 100 to $500 \mu \mathrm{m}$.

The results at $V_{\text {bias }}=-0.1 \mathrm{~V}$ and $-0.3 \mathrm{~V}$ are shown in Fig. 3 and values of the determined parameters are presented in Table I. Based on these results, it is concluded that device with $\mathrm{NH}_{4} \mathrm{~F}$ passivation increases the surface leakage current (over two orders of magnitude) compared to the others samples, while bulk current density remains at a similar level. That results indicates that the surface leakage current is not a dominant dark current mechanism at HOT conditions. 

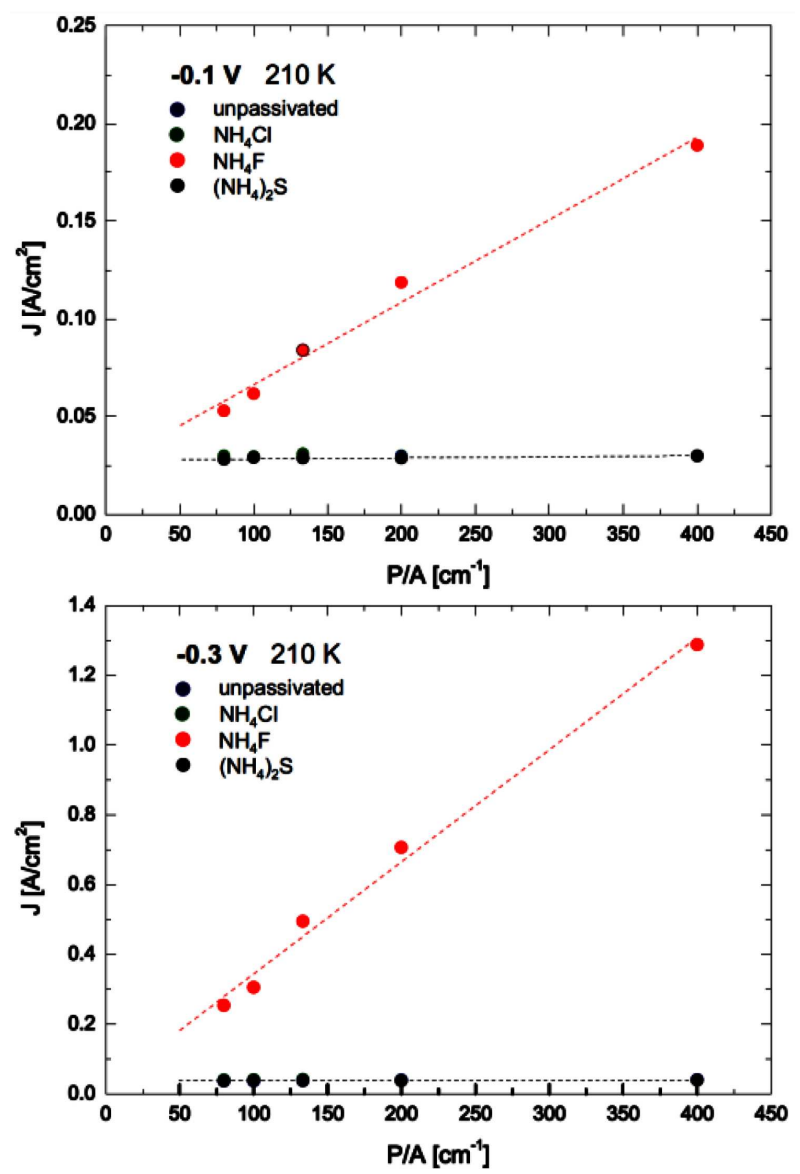

Fig. 3. The dark current density versus perimeter to area $P / A$ ratio at a bias $-0.1 \mathrm{~V}$ and $-0.3 \mathrm{~V}$.

\section{TABLE I}

The dark current components for $\mathrm{NH}_{4} \mathrm{~F}$ passivation solution and other measurement samples under $V_{\text {bias }}=-0.1$ and $-0.3 \mathrm{~V}$

\begin{tabular}{c|c|c|c|c}
\hline \hline & \multicolumn{2}{|c|}{$J_{\text {surf }}\left[\mathrm{A} \mathrm{cm}^{-1}\right]$} & \multicolumn{2}{c}{$J_{\text {bulk }}\left[\mathrm{A} \mathrm{cm}^{-2}\right]$} \\
\cline { 2 - 5 } & $-0.1 \mathrm{~V}$ & $-0.3 \mathrm{~V}$ & $-0.1 \mathrm{~V}$ & $-0.3 \mathrm{~V}$ \\
\hline $\mathrm{NH}_{4} \mathrm{~F}$ & $4 \times 10^{-4}$ & $3.7 \times 10^{-3}$ & $24.2 \times 10^{-3}$ & $35.8 \times 10^{-3}$ \\
Other & $6 \times 10^{-6}$ & $6 \times 10^{-6}$ & $27.7 \times 10^{-3}$ & $37.7 \times 10^{-3}$
\end{tabular}

The quality of the surfaces were investigated by XPS measurements. The XPS spectra were carried out with monochromatic $\mathrm{Al} K_{\alpha} \mathrm{X}$-ray source with a photon energy of $1486 \mathrm{eV}$ under ultrahigh vacuum. The scans were done at room temperature and the CasaXPS software were used to fit the data.

On the XPS spectra the dominant peaks were recognized as $\mathrm{In} 4 d$ at $18 \mathrm{eV}, \mathrm{Sb} 4 d$ at $36-30 \mathrm{eV}$, As $3 d$ at $45 \mathrm{eV}$, As $2 \mathrm{p}$ at $140 \mathrm{eV}, \mathrm{S} 2 p$ at $162 \mathrm{eV}$, In $3 d$ at $454-$ $442 \mathrm{eV}$ and $\mathrm{Sb} 3 d$ at $540-528 \mathrm{eV}$. Obtained results indicate that the concentration of oxygen on the surface is lower in the $\mathrm{S}$ and $\mathrm{Cl}$ treated samples. The $\mathrm{O} 1 s$ signals are weaker and are similar to As $3 d$ and In $4 d$ signals. Only sulphur treatment eliminates almost all oxides from the surface. Table II summarizes the relative ratios of As and $\mathrm{O}$ elements with the In $3 \mathrm{~d}_{5 / 2}$ at $444 \mathrm{eV}$. The ratio of $\mathrm{O} 1 s / \mathrm{In} 3 d$ and As $3 d / \mathrm{In} 3 d$ is lowest for sulphur treatment. Low value indicates that this sample should have the best parameters in long term stability. As $3 d$ spectra were collected for binding energy range $46-40 \mathrm{eV}$. The peak at $44 \mathrm{eV}$ and $42 \mathrm{eV}$ correspond to oxidized arsenic and As-In bond, respectively [9]. The highest intensity of $\mathrm{O} 1 s$ and As $3 d$ peaks were observed for $\mathrm{NH}_{4} \mathrm{~F}$ treatment. During the anodization process the fluorine react with the surface and creates secondary compounds which then are easily reoxidized. The chlorine treatment does not change the surface or after the passivation the surface is reoxidized. Figure $4 \mathrm{f}$ shows the decrease of Sb-oxide peaks after $\mathrm{S}$ and $\mathrm{Cl}$ treatment. This is in agreement with the result summarize in Table II and Fig. 4b where signal from $\mathrm{Sb} 4 d$ and Sb-oxide peak [10] (associated with $\mathrm{Sb}_{2} \mathrm{O}_{3}$ and $\mathrm{Sb}_{2} \mathrm{O}_{5}$ ) decreased. The weaker signals of $\mathrm{Sb}-$ $\mathrm{O}, \mathrm{Sb}-\mathrm{In}, \mathrm{As}-\mathrm{In}$ and higher intensities of In-S are an evidence of In-S layer on the top in $\left(\mathrm{NH}_{4}\right)_{2} \mathrm{~S}$ treated device and oxide layers in other devices. In Fig. $4 \mathrm{~d}$ the In $3 d_{5 / 2} \mathrm{~S}$ peak $(445 \mathrm{eV})$ is observed for the $\left(\mathrm{NH}_{4}\right)_{2} \mathrm{~S}$ sample. The peak in the unpassivated sample is wider and shifted towards In-As peak. The width of this peak and in $\mathrm{Cl}, \mathrm{F}$ passivated samples indicates also oxide layer on the top.

TABLE II

Intensity ratio of In $3 \mathrm{~d}_{5 / 2}$ vs. different elements of InAsSb samples after passivation.

\begin{tabular}{l|c|c|c}
\hline \hline Sample & $\mathrm{O} 1 s /$ In $3 d_{5 / 2}$ & As $3 d /$ In $3 d_{5 / 2}$ & In $4 d /$ In $3 d_{5 / 2}$ \\
\hline unpassivated & $17 / 26=0.65$ & $12 / 26=0.46$ & $28 / 26=1.08$ \\
$\left(\mathrm{NH}_{4}\right)_{2} \mathrm{~S}$ & $5 / 24=0.2$ & $6 / 24=0.25$ & $30 / 24=1.25$ \\
$\mathrm{NH}_{4} \mathrm{~F}$ & $18 / 19=0.94$ & $14 / 19=0.74$ & $20 / 19=1.05$ \\
$\mathrm{NH}_{4} \mathrm{Cl}$ & $13 / 26=0.5$ & $16 / 26=0.62$ & $26 / 26=1.0$
\end{tabular}

\section{Summary and conclusions}

We have demonstrated the result of passivated and unpassivated InAsSb barrier diode on GaAs substrate operating at HOT conditions.

The comparison of 3 anodic films showed that the sulphur ECP treated sample exhibits the most uniform surface with reduced amount of oxide layer on the top. The same level of dark current were reached for unpassivated devices and after sulphur and chloride treatment. This means that our proposed two step passivation technique connected with sulphur treatment was not destructive to InAsSb diode. What is more that results indicates that the surface leakage current is not a dominant dark current mechanism at HOT conditions. In that case the passivation layer in bulk barrier diode might play a main role as mechanical barrier to atmosphere, production technology, and might be crucial for long-term stability studies [11]. The XPS measurements confirmed the destructive nature of fluorine treatment. Future investigation of the long term stability studies will be done for passivated samples. 

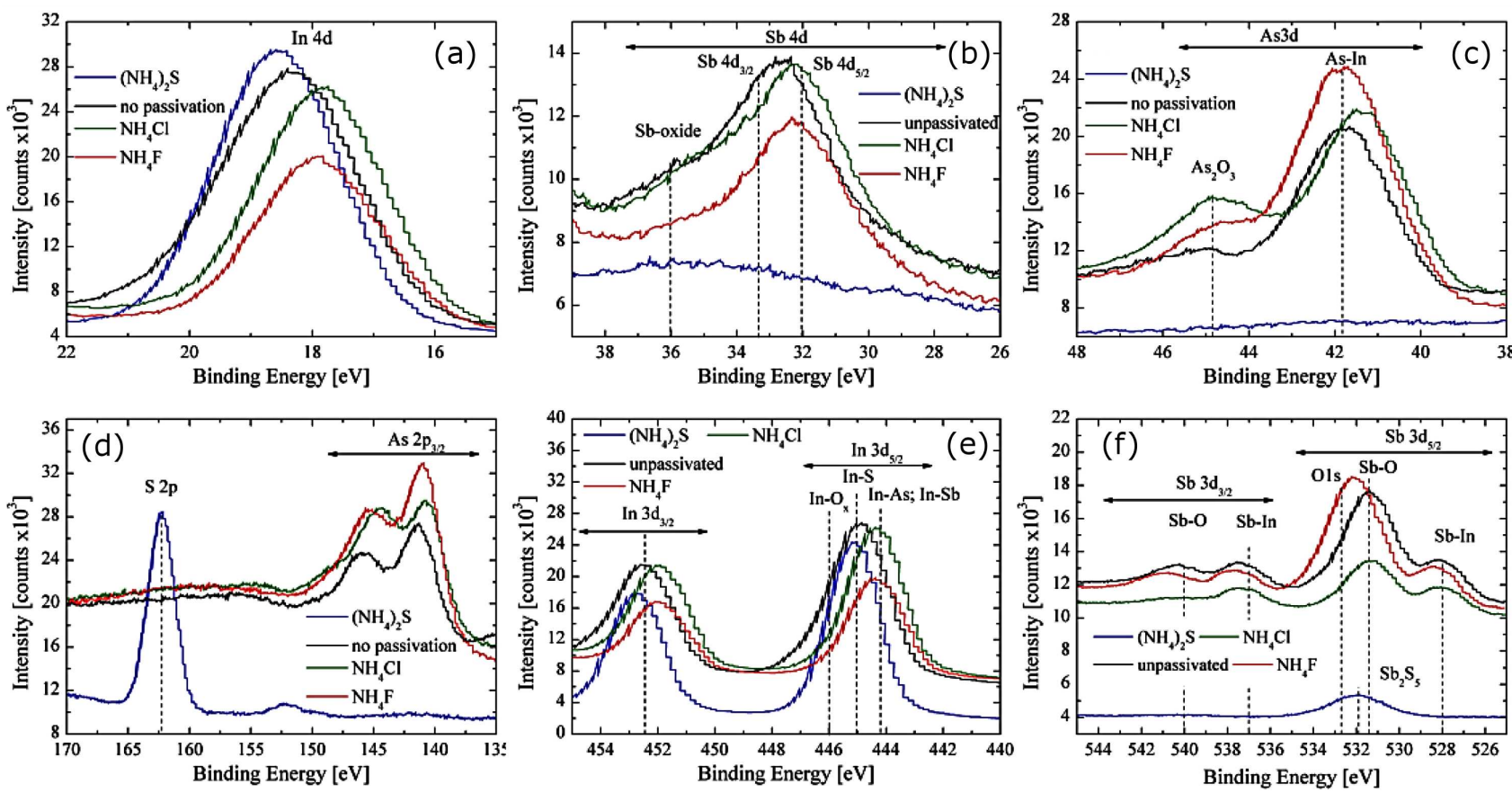

Fig. 4. XPS spectra of (a) In 4d, (b) Sb 4d, (c) As $3 d$, (d) S $2 p$ and As $2 p$, (e) In $3 d$, (f) Sb $3 d$ for ECP and unpassivated structure of InAsSb diode.

\section{Acknowledgments}

The authors would like to acknowledge the support by Polish National Science Centre: grant no. PRELUDIUM/UMO-2015/19/N/ST7/01508, and the National Centre for Research and Development (Poland): grant no. POIR.04.01.04-00-0027/16.

\section{References}

[1] A. Rogalski, Infrared Detectors, 2nd ed., CRC Press, 2011.

[2] T.P. Smirnova, A.N. Golubenko, N.F. Zacharchuk, V.I. Belyi, G.A. Kokovin, N.A. Valisheva, Thin Solid Films 76, 11 (1981).

[3] B. Klein, K. Artyushkova, E.A. Plis, A. Jamus, S. Maji, L. Casias, M.N. Kutty, S. Krishna, Infrared Phys. Technol. 70, 66 (2015).
[4] G.P. Schwartz, W.A. Sunder, J.E. Griffiths, G.J. Gualtieri, Thin Solid Films 103, 3 (1983).

[5] G. Hollinger, R. Skheyta-Kabbani, M. Gendry, Phys. Rev. B 49, 11159 (1994).

[6] X. Du, G.R. Savich, B.T. Marozas, G.W. Wicks, J. Electron. Mater. 47, 1038 (2018).

[7] D.E Sidor, G.R. Savich, G.W. Wicks, J. Electron. Mater. 45, 4663 (2016).

[8] K. Banerjee, S. Ghosh, E.A. Plis, J. Electron. Mater. 39, 2210 (2010).

[9] D.Y. Petrovykh, M.J. Yang, L.J. Whitman, Surf. Sci. 523, 231 (2003).

[10] Q. Wang, X. Li, A. Zhang, S. Almqvist, A. Karim, B. Noharet, J.Y. Anderson, Proc. SPIE 8353, 83538353-8 (2012).

[11] K. Michalczewski, F. Ivaldi, Ł. Kubiszyn, D. Benyahia, J. Ciosek, J. Boguski, Proc. SPIE 10830, 10830-10830-5 (2018). 